\title{
Article \\ Experiences and Interactions with the Healthcare System in Transgender and Non-Binary Patients in Austria: An Exploratory Cross-Sectional Study
}

\author{
Lovro Markovic ${ }^{1,2}{ }^{\mathbb{D}}$, Daragh T. McDermott ${ }^{3} \mathbb{D}$, Sinisa Stefanac ${ }^{4, * \mathbb{D}}$, Radhika Seiler-Ramadas ${ }^{1}$, \\ Darina Iabloncsik ${ }^{1}$, Lee Smith ${ }^{5}$ D , Lin Yang ${ }^{6,7}$ D, Kathrin Kirchheiner ${ }^{8}$, Richard Crevenna ${ }^{2}$ and Igor Grabovac $^{1}$ (D)
}

check for updates

Citation: Markovic, L.;

McDermott, D.T.; Stefanac, S.; Seiler-Ramadas, R.; Iabloncsik, D.; Smith, L.; Yang, L.; Kirchheiner, K.; Crevenna, R.; Grabovac, I.

Experiences and Interactions with the Healthcare System in Transgender and Non-Binary Patients in Austria: An Exploratory Cross-Sectional Study Int. J. Environ. Res. Public Health 2021, 18, 6895. https://doi.org/10.3390/ ijerph18136895

Academic Editor: Dustin T. Duncan

Received: 29 May 2021

Accepted: 24 June 2021

Published: 27 June 2021

Publisher's Note: MDPI stays neutra with regard to jurisdictional claims in published maps and institutional affiliations.

Copyright: (c) 2021 by the authors. Licensee MDPI, Basel, Switzerland. This article is an open access article distributed under the terms and conditions of the Creative Commons Attribution (CC BY) license (https:// creativecommons.org/licenses/by/ $4.0 /)$.
1 Department of Social and Preventive Medicine, Centre for Public Health, Medical University of Vienna, 1090 Vienna, Austria; lovro.markovic@meduniwien.ac.at (L.M.); radhika.seiler-ramadas@meduniwien.ac.at (R.S.-R.); darina.iabloncsik@gmail.com (D.I.); igor.grabovac@meduniwien.ac.at (I.G.)

2 Department of Physical Medicine, Rehabilitation and Occupational Medicine, Medical University of Vienna, 1090 Vienna, Austria; richard.crevenna@meduniwien.ac.at

3 NTU Psychology, School of Social Sciences, Nottingham Trent University, Nottingham NG1 4FQ, UK; daragh.mcdermott@ntu.ac.uk

4 Institute of Outcomes Research, Centre for Medical Statistics, Informatics and Intelligent Systems, Medical University of Vienna, 1090 Vienna, Austria

5 Cambridge Centre for Sport and Exercise Sciences, Anglia Ruskin University, Cambridge CB1 1PT, UK; lee.smith@aru.ac.uk

6 Department of Cancer Epidemiology and Prevention Research, Cancer Care Alberta, Alberta Health Services, Calgary, AB T2S 3C3, Canada; lin.yang@albertahealthservices.ca

7 Departments of Oncology and Community Health Sciences, Cumming School of Medicine, University of Calgary, Calgary, AB T2N 1N4, Canada

8 Department of Radiation Oncology, Medical University of Vienna, 1090 Vienna, Austria; kathrin.kirchheiner@meduniwien.ac.at

* Correspondence: sinisa.stefanac@meduniwien.ac.at

Abstract: Medical care of transgender and non-binary (TNB) patients if often a complex interdisciplinary effort involving a variety of healthcare workers (HCWs) and services. Physicians not only act as gatekeepers to routine or transitioning therapies but are also HCWs with the most intimate and time-intensive patient interaction, which influences TNB patients' experiences and health behaviors and healthcare utilization. The aim of this study was to investigate the physician-patient relationship in a sample of TNB individuals within the Austrian healthcare system, and explore its associations with sociodemographic, health-, and identity-related characteristics. A cross-sectional study utilizing an 56-item online questionnaire, including the Patient-Doctor Relationship Questionnaire 9 (PDRQ-9), was carried out between June and October 2020. The study involved TNB individuals 18 or older, residing in Austria, and previously or currently undergoing medical transition. In total, 91 participants took part, of whom $33.0 \%$ and $25.3 \%$ self-identified as trans men and trans women, respectively, and $41.8 \%$ as non-binary. Among participants, $82.7 \%$ reported being in the process of medical transitioning, 58.1\% perceived physicians as the most problematic HCWs, and $60.5 \%$ stated having never or rarely been taken seriously in medical settings. Non-binary participants showed significantly lower PDRQ-9 scores, reflecting a worse patient-physician relationship compared to trans male participants. TNB patients in Austria often report negative experiences based on their gender identity. Physicians should be aware of these interactions and reflect potentially harmful behavioral patterns in order to establish unbiased and trustful relations.

Keywords: healthcare utilization; trans; transgender; non-binary; gender-nonconforming; physicianpatient relationship; health behavior 


\section{Introduction}

Despite increasing social visibility and legal recognition, gender-minority individuals, including transgender (people whose gender identity differs from the normatively expected based on sex as assigned at birth) and non-binary (people whose gender identity does not match the binary conceptualization of gender) (TNB) people [1], still face social marginalization, discrimination, and numerous barriers in the healthcare system [2-4]. Experiencing transphobia (i.e., discrimination based on gender expression or identity that differs from the sex assigned at birth) has been a recognized issue in accessing healthcare services, including primary care as well as specialized secondary and tertiary care $[2,4,5]$. Barriers to accessing healthcare for TNB people are multifarious and range from subtle (such as ill-adapted environments and lack of knowledgeable personnel) to direct (such as denial of health care or abuse) [6,7]. In fact, results of a U.S.-based study reported that $19 \%$ of transgender identifying patients were denied medical care, with this proportion rising to $28 \%$ in transgender patients of color and $2 \%$ overall reported to have experienced physical violence in the physician's office [8]. These reports are further compounded by robust evidence indicating higher prevalence of mental health problems in TNB people [9]. For example, studies report that depression is twice as prevalent in TNB youth compared to cisgender (i.e., those whose gender identity matches the gender assigned at birth) youth $[9,10]$. Moreover, $39 \%$ of TNB adults reported psychological distress over the past month and $40 \%$ reported suicide attempts over their lifetime [9]. Many of these mental health issues evolve as a result of experiencing prejudice and discrimination attributable to their gender identity (i.e., transphobia). Owen-Smith et al. reported that depression correlated with negative perceptions of community tolerance in TNB adults [11].

Mental health outcomes may be improved through services that provide empowering and affirming healthcare (i.e., provide respectful support to the patient's self-identified gender identity, using appropriate chosen pronouns and names) [12]. For example, a study by Tucker et al. reported a decrease in suicidal ideation in trans U.S. army veteran patients who received affirming care compared to those who did not [13]. The results seem to be similar across age groups, as reports also showed that transgender prepubescent children (who have a binary gender identity that does not align with their sex as assigned at birth) who received affirming care and were allowed to present in their gender identity in everyday life had lower rates of depression and anxiety, which did not significantly differ from the two control groups included in this study (i.e., their siblings and agematched non-transgender children) [14]. Furthermore, TNB adults who received medical care from healthcare providers that they considered to be affirming had lower levels of depression and suicidal ideation compared to TNB adults who reported not having a trans-affirmative healthcare provider [15]. Results from an Australian study showed that gender diverse Australians who felt respected by, and comfortable with, their general practitioners reported better mental health [16].

The importance of providing empowering and affirming healthcare for TNB patients has been outlined in various studies, and is confirmed by various prominent international guidelines and standards on transgender and non-binary care, yet studies of experiences with TNB patients show an immense lack of knowledge and information on TNB health from healthcare providers. In 2010, 50\% of the 6450 surveyed transgender individuals reported having to educate their healthcare providers on various issues of transgender medical care, which is challenging and may be especially harmful in the patient-physician interaction [8]. This lack of knowledge and information is likely a result of training deficits on TNB health during medical education. For example, Chisolm-Starker et al. reported that even though $88 \%$ of emergency care staff provided care to transgender patients, $82.5 \%$ never received any formal training on the specific aspects of working with this population [17]. Lack of education combined with stigma contributes further to negative interactions with physicians and other professionals in healthcare settings [18]. Moreover, in addition to lack of training, there are results indicating that healthcare providers may hold bias towards LGBT patients that emanates from their lived experiences and personal 
political or religious views $[19,20]$. Even in healthcare providers that were receptive to providing LGBT competent care, some studies indicated that there are still enacted microaggressions that further maintain negative experiences of TNB people in healthcare. These often include nullifying LGBT experiences or their importance in the clinical setting, or through maintenance of stereotypes [21].

Unfavorable communication and interaction may include not understanding the needs of TNB patients, or not understanding the differences between constructs such as sex and gender or between sexual orientation and gender identity, which mostly stem from a lack of exposure to TNB people and education [7]. This may lead physicians to try to fit TNB patients into binary protocols and not provide affirmative care [22,23]. Negative experiences in the healthcare setting may not only be detrimental to physical and mental health, but also influence healthcare utilization, reduce quality of life, and increase rates of self-reported disability [18,24]. Moreover, considering the need to establish a medical precondition (i.e., diagnosis) in order to start medical transitioning, TNB patients may feel compelled to provide healthcare professionals with fictitious narratives in order to ensure the start of the medical transitioning process $[2,25,26]$. This constitutes yet another barrier for TNB patients in the healthcare setting and further underlines the importance of supportive patientphysician interactions. In Austria, initiating a medical transitioning process involves an assessment by three independent mental health professionals-a psychotherapist, a psychiatrist, and a psychologist-all of whom need to give an independent positive referral. These are summarized as a joint statement by a so-called "coordinator of care" as chosen by the patient, and may be any medical professional involved in the transitioning process [27] Afterwards, patients may start with medical gender-affirming interventions as well as legal transitioning (i.e., official name change or gender designation or legal documents). This brings TNB patients in contact with many HCWs and institutions, possibly reducing meaningful interactions and diminishing patient-physician trust.

Despite expanding literature on various barriers in healthcare, little is known about the patient-physician interactions and experiences in healthcare from TNB patients. To our knowledge, this is the first study of its kind conducted in Austria. The legal and social changes that have happened in Austria over the past decade have led to an increase in legal rights for TNB people, such as the right to change their legal gender or change their first name before any surgical interventions (a gender dysphoria diagnosis is still necessary) [28]. However, Austria has been cited by various international organizations for the lack of implementing policies that would further depathologize TNB identities [29]. To the best of our abilities, we were unable to find any studies that have provided any data on experiences of TNB people in the healthcare system in Austria. There have been sporadic results from various reports outlining that TNB patients in Austria tend to avoid accessing healthcare due to fear of prejudicial treatment by healthcare professionals and complete lack of competent and affirmative care [30,31]. These are, however, mostly anecdotal and do not provide additional insights. Given this complete lack of data on TNB experiences in healthcare from Austria and a paucity of reports from Central Europe [32], our aim was to conduct a cross-sectional study to explore the patient-physician relationship, experiences of TNB patients, transitioning facets, and health status in transgender and non-binary people in Austria. It is the hope that the results of this exploratory study serve as a base for further research highlighting the experiences of TNB people in the healthcare system in Austria, but also catalyze the needed changes to provide affirmative and competent care that TNB patients in Austria deserve.

\section{Participants and Methods}

A cross-sectional study was carried out between June and October 2020 using a selfadministered, online-based questionnaire comprising 56 items, which took about $15 \mathrm{~min}$ to complete, and was hosted on the SoSci Survey platform (www.soscisurvey.de, accessed on 27 June 2021) with servers based in Germany, compliant with the General Data Protection Regulation (GDPR). 


\subsection{Participants and Recruitment}

Participants in this study were recruited among individuals who were 18 years old or older, residing in Austria, and self-identifying as TNB who currently were or previously had been in the process of medical transitioning. The link to the study was distributed through various institutions and organizations involved in gender minority work, as well as through social media platforms such as Facebook, Twitter, and Instagram. This study was approved by the Ethics Committee of the Medical University of Vienna under study number 1199/2020 and was performed in accordance with the Declaration of Helsinki (1964, including subsequent revisions), as well as research guidelines developed by the European Commission. Participation in the study was voluntary, anonymous, required participants explicit consent, and involved no financial or any other incentives. No identifying data were saved from the participants, including the IP addresses.

\subsection{Questionnaire}

The 56 questionnaire items used in this analysis assessed sociodemographic data, gender identity and sexual orientation, aspects of medical and legal transitioning, health status and behavior, as well as experiences in healthcare settings:

1. Gender identity and satisfaction with gender expression (3 items): This initial part of the questionnaire included questions on gender assigned at birth (single-choice question: "Which sex was assigned to you at birth?" with answers being "male," "female," and an open-ended text entry); the participants' current gender identity (multiplechoice question: "How would you best describe your gender identity?" with answers of "male," "female," "transgender (FtM, MtF)," "non-binary," and an open-ended text entry); the satisfaction with one's current gender expression (single-choice question: "How satisfied are you with your current gender expression?," with answers ranging on a 5-point Likert type scale: " 1 = very satisfied," " $3=$ neither satisfied nor dissatisfied," and " $5=$ very dissatisfied"). The questions on gender identity were based on the "two-step approach" and in line with the current recommendations of queries on gender identity in transgender and non-binary participants [33]. Additionally, prior to the study launch the questionnaire draft was presented to transgender and non-binary people to make sure the questions were understandable and non-discriminatory.

2. Sociodemographic questions and sexual orientation (15 items): Participants were asked to provide their, age, country of birth, citizenship, their current country of residence, urban characteristics of their place of residence, highest completed level of education, employment, monthly income, living situation, their sexual orientation, and degree of outness (in general and in various areas of daily life).

3. Aspects of medical and legal transitioning (14 items): Participants were asked to indicate whether they had already initiated medical transitioning and at what age, the duration of the initial psychological assessment before transitioning began, the appointed coordinator of care, various gender affirming medical procedures that they planned to have or had undergone, and whether they had legally changed their name and gender indication on official documents.

4. General experiences of violence ( 2 items): Participants were asked whether they have experienced violence due to their gender identity and what forms of violence they had experienced.

5. Health status and behaviors (4 items): Participants were asked to indicate whether they were ever diagnosed by a healthcare professional with a chronic illness or a mental health condition (other than receiving the "necessary" diagnosis of "gender dysphoria"), and on the frequency and amount of tobacco and alcohol they consumed.

6. Healthcare utilization and experiences in healthcare settings (9 items): Participants were asked whether they had consulted a physician over the past year and whether they would seek medical assistance again the future, whether they had ever been deliberately misgendered by a healthcare professional even after stating their pronouns, whether they had experienced any form of violence while in the healthcare 
setting due to their gender identity, whether they had ever been denied treatment due to their gender identity, whether they had ever reported such an incident and to whom, and their perception of the most problematic professional group within the healthcare system.

7. Doctor-patient relationship (9 items): This was assessed by the Patient-Doctor Relationship Questionnaire (PDRQ-9). The PDRQ-9 was developed from the Helping Alliance Questionnaire, which measures the therapeutic alliance in psychotherapy and provides researchers with a brief measure of therapeutic aspects of the doctorpatient relationship in primary care settings [34]. The PDRQ-9 has been shown to have high reliability and validity $[34,35]$. For the purposes of this study, we used the validated German-language version [36]. The PDRQ-9 comprises 9 positively worded statements on various aspect of satisfaction with the doctor-patient relationship, to which the participants indicate the appropriateness of each statement on a 5-point Likert-type scale (" $1=$ not at all appropriate," " $3=$ appropriate," and " $5=$ totally appropriate"). The final score (5-45 points) is produced as a sum of all 9 items, with higher scores indicating a better doctor-patient relationship [34]. As TNB patients in Austria have to have a primary coordinator of care to coordinate the transitioning process (which may or may not be a primary care physician), we asked the participants to answer the questionnaire with their coordinator of care in mind. In our survey, the internal consistency was determined by Cronbach's alpha and was found to be 0.96 , indicating high internal consistency.

\subsection{Statistical Analysis}

Data were analyzed with SPSS v27.0 for MacOS (Reference: IBM Corp. Released 2020. IBM SPSS Statistics for MacOS, Version 27.0. Armonk, NY: IBM Corp). All variables were analyzed descriptively, with mean values and standard deviations shown for continuous variables, and frequencies and percentages for categorical data. One-way ANOVA was performed to compare the PDRQ-9 score between the gender identity categories, including a Tukey HSD post-hoc analysis to pinpoint the group pairs with a significant difference of mean PDRQ-9 scores.

\section{Results}

The link to the online questionnaire was clicked on a total of 1280 times, and 139 participants proceeded to fill out the questionnaire. After applying the inclusion criteria (i.e., over the age of 18 , residing in Austria, self-identifying as transgender or non-binary, having started medical or legal transitioning), 91 entries were eligible for analysis.

\subsection{Sociodemographics}

The majority of study participants were Austrian citizens (92.3\%), with a mean age of $29(\mathrm{SD}=10.0)$, residing in a city $(68.1 \%)$, and having completed secondary education (37.4\%). A total of 56.7\% were in paid employment, earning up to EUR $1000 /$ month (59.6\%), and were living alone or in a shared flat $(57.0 \%)$. Further descriptive variables of the sample are presented in Table 1.

\subsection{Identity-Related Characteristics}

Seventy percent of participants were assigned female at birth and $41.8 \%$ of participants identified as non-binary, and almost one third identified as bisexual. Most reported being "somewhat" or "very" satisfied with their gender expression, and almost all were "out" (i.e., did not conceal) their gender identity and sexual orientation, as presented in Table 1. 
Table 1. Sociodemographic and identity characteristics of the study sample.

\begin{tabular}{|c|c|}
\hline Variable & Participants $(N=91)$ \\
\hline \multicolumn{2}{|l|}{ Age } \\
\hline $\mathrm{M}^{1}, \mathrm{SD}^{1}$ & $29.0(10.0)$ \\
\hline \multicolumn{2}{|l|}{ Austrian citizenship $(n, \%)$} \\
\hline No & $4(4.4 \%)$ \\
\hline Yes & $87(95.6 \%)$ \\
\hline \multicolumn{2}{|l|}{ Geographical area $(n, \%)$} \\
\hline Countryside/town & $29(31.9 \%)$ \\
\hline City & $62(68.1 \%)$ \\
\hline \multicolumn{2}{|l|}{ Education $(n, \%)$} \\
\hline None/Primary/Vocational & $24(26.4 \%)$ \\
\hline Secondary & $34(37.4 \%)$ \\
\hline Tertiary & $33(36.3 \%)$ \\
\hline \multicolumn{2}{|l|}{ Income $(n, \%)$} \\
\hline Up to EUR $1000 /$ month & $53(59.6 \%)$ \\
\hline Up to EUR $2000 /$ month & $24(27.0 \%)$ \\
\hline$>2000 \mathrm{EUR} /$ month & $12(13.5 \%)$ \\
\hline \multicolumn{2}{|l|}{ Employment status $(n, \%)$} \\
\hline No paid employment & $39(43.3 \%)$ \\
\hline In paid employment & $51(56.7 \%)$ \\
\hline \multicolumn{2}{|l|}{ Living situation $(n, \%)$} \\
\hline Single/Alone/Shared flat & $45(57.0 \%)$ \\
\hline With partner & $21(26.6 \%)$ \\
\hline Other & $13(16.5 \%)$ \\
\hline \multicolumn{2}{|l|}{ Gender assigned at birth $(n, \%)$} \\
\hline Female & $64(70.3 \%)$ \\
\hline Male & $26(28.6 \%)$ \\
\hline Other & $1(1.1 \%)$ \\
\hline \multicolumn{2}{|l|}{ Gender identity $(n, \%)$} \\
\hline Trans man & $30(33.0 \%)$ \\
\hline Trans woman & $23(25.3 \%)$ \\
\hline Non-binary person & $38(41.8 \%)$ \\
\hline \multicolumn{2}{|l|}{ Sexual orientation $(n, \%)$} \\
\hline Heterosexual & $10(11.0 \%)$ \\
\hline Homosexual & $22(24.2 \%)$ \\
\hline Bisexual & $30(33.0 \%)$ \\
\hline Asexual & $3(3.3 \%)$ \\
\hline Queer/Pansexual & $26(28.6 \%)$ \\
\hline \multicolumn{2}{|l|}{ Gender expression $(n, \%)$} \\
\hline Very dissatisfied & $9(9.9 \%)$ \\
\hline Somewhat dissatisfied & $10(11.0 \%)$ \\
\hline Neutral & $10(11.0 \%)$ \\
\hline Somewhat satisfied & $41(45.1 \%)$ \\
\hline Very satisfied & $21(23.1 \%)$ \\
\hline \multicolumn{2}{|l|}{ Out $(n, \%)$} \\
\hline Yes & $90(98.9 \%)$ \\
\hline No & $1(1.1 \%)$ \\
\hline
\end{tabular}

${ }^{1} \mathrm{M}=$ mean value (arithmetic mean), $\mathrm{SD}=$ standard deviation.

\subsection{Medical and Legal Transitioning}

The mean age at the start of medical transitioning was 26 . More than $80 \%$ were in the process of medical transitioning at the time of the study, with their psychotherapist having coordinated the referral statements. Mean waiting time for positive referral to start the medical transitioning was around 10 months. Overall, $82.4 \%$ of transitioning participants had been on hormone replacement therapy for a median duration of 35 months at the time of the survey, and $52.7 \%$ had not had surgical interventions (e.g., vaginoplasty/phalloplasty). Of those who had already undergone surgery, almost all had had one or more procedures completed in Austria. Concerning other types of therapeutic interventions, most reported 
psychotherapy. Regarding legal transitioning, most had changed their name and their legal gender. Details are summarized in Table 2.

Table 2. Aspects of transitioning and health-related characteristics.

\begin{tabular}{|c|c|}
\hline Variable & Participants $(N=91)$ \\
\hline \multicolumn{2}{|c|}{ Medically transitioning $(n, \%)$} \\
\hline No & $16(17.6 \%)$ \\
\hline Yes & $75(82.4 \%)$ \\
\hline \multicolumn{2}{|c|}{ * Age at begin of transitioning } \\
\hline $\mathrm{M}(\mathrm{SD})$ & $26.2(8.9)$ \\
\hline \multicolumn{2}{|c|}{ * Coordinator of referral statement $(n, \%)$} \\
\hline Psychotherapist & $55(75.3 \%)$ \\
\hline Psychologist & $4(5.5 \%)$ \\
\hline Psychiatrist & $6(8.2 \%)$ \\
\hline Gynecologist & $1(1.4 \%)$ \\
\hline Endocrinologist & $1(1.4 \%)$ \\
\hline Other & $6(8.2 \%)$ \\
\hline \multicolumn{2}{|c|}{ * Duration of wait for positive referral } \\
\hline $\mathrm{M}(\mathrm{SD})$ & $10.2(7.7)$ \\
\hline \multicolumn{2}{|c|}{ * Hormonal replacement therapy $(\mathrm{HRT})(n, \%)$} \\
\hline No & $9(12.3 \%)$ \\
\hline Yes & $64(87.7 \%)$ \\
\hline \multicolumn{2}{|l|}{ * Months on HRT } \\
\hline $\mathrm{M}(\mathrm{SD})$ & $35.5(38.5)$ \\
\hline \multicolumn{2}{|c|}{ * Gender-affirming surgery $(n, \%)$} \\
\hline Chest (top) & $20(27.0 \%)$ \\
\hline Other ( \pm top $)$ & $15(20.3 \%)$ \\
\hline None & $39(52.7 \%)$ \\
\hline \multicolumn{2}{|c|}{$* *$ Surgery abroad $(n, \%)$} \\
\hline Yes & $2(7.4 \%)$ \\
\hline No & $25(92.6 \%)$ \\
\hline \multicolumn{2}{|c|}{ * Speech therapy $(n, \%)$} \\
\hline No & $52(74.3 \%)$ \\
\hline Yes & $15(21.4 \%)$ \\
\hline \multicolumn{2}{|l|}{ * Epilation $(n, \%)$} \\
\hline No & $53(79.1 \%)$ \\
\hline Yes & $14(20.9 \%)$ \\
\hline \multicolumn{2}{|c|}{ * Psychotherapy (beyond the scope for referrals) $(n, \%)$} \\
\hline No & $22(32.8 \%)$ \\
\hline Yes & $45(67.2 \%)$ \\
\hline \multicolumn{2}{|c|}{ Further medical steps desired $(n, \%)$} \\
\hline No & $37(41.6 \%)$ \\
\hline Yes & $52(58.4 \%)$ \\
\hline \multicolumn{2}{|c|}{ Location of potential further medical steps $(n, \%)$} \\
\hline Austria & $48(73.8 \%)$ \\
\hline Abroad & $17(26.2 \%)$ \\
\hline \multicolumn{2}{|c|}{ Legal name change $(n, \%)$} \\
\hline Yes & $69(75.8 \%)$ \\
\hline No, but planned & $19(20.9 \%)$ \\
\hline No, not planned & $3(3.3 \%)$ \\
\hline \multicolumn{2}{|c|}{ Legal gender change $(n, \%)$} \\
\hline Yes & $59(64.8 \%)$ \\
\hline No, but planned & $27(29.7 \%)$ \\
\hline No, not planned & $5(5.5 \%)$ \\
\hline \multicolumn{2}{|c|}{ Chronic somatic illness $(n, \%)$} \\
\hline Yes & $32(35.2 \%)$ \\
\hline No & $59(64.8 \%)$ \\
\hline
\end{tabular}


Table 2. Cont.

\begin{tabular}{cc}
\hline Variable & Participants $(\boldsymbol{N}=\mathbf{9 1})$ \\
\hline Mental illness $(\mathrm{n}, \%)$ & \\
Yes & $52(57.1 \%)$ \\
No & $39(42.9 \%)$ \\
Smoking status $(n, \%)$ & $11(12.1 \%)$ \\
Yes & $33(36.3 \%)$ \\
No, ex-smoker & $47(51.6 \%)$ \\
Never smoked & \\
Alcohol consumption $(n, \%)$ & $19(20.9 \%)$ \\
Never & $58(63.7 \%)$ \\
Occasionally & $9(9.9 \%)$ \\
Weekly & $5(5.5 \%)$ \\
Daily & \\
\hline${ }^{*}$ Considering only participants who were medically transitioning $(n=75) .{ }^{* *}$ Considering only participants who
\end{tabular}
underwent gender-affirming surgery $(n=35)$.

\subsection{Health Status and Behavior}

More than a third of participants had a chronic disease diagnosed by a physician, and almost two thirds had a mental health diagnosis from a mental health professional. The majority never smoked, and "occasionally" consumed alcohol (Table 2).

\subsection{Experiences in Healthcare Settings}

Most participants had consulted a physician in the past year, and would "probably" seek medical attention in future for a somatic illness, whereas a higher proportion stated the same for mental illness, as shown in Table 3. Almost two thirds of participants reported not being taken seriously in medical settings, and over $20 \%$ stated being "often" and "very often" misgendered by healthcare workers (HCWs), even after stating their gender identity and pronouns. Almost $8 \%$ said they experienced verbal violence from $\mathrm{HCWs}$, whereas only $4.9 \%$ reported such incidents. More than $13 \%$ reported having been denied medical care due to their gender identity, and more than half perceived physicians as the most problematic members of the healthcare workforce (Table 3).

Table 3. Experiences in healthcare settings.

\begin{tabular}{cc}
\hline Variable & Participants $(\mathbf{N}=\mathbf{9 1})$ \\
\hline Consulted a physician in the past year $(n, \%)$ & \\
Yes & $69(75.8 \%)$ \\
No & $22(24.2 \%)$ \\
Planned somatic healthcare utilization, if \\
needed $(n, \%)$ & \\
Definitely not & \\
Probably not & $0(0.0 \%)$ \\
Maybe & $4(4.4 \%)$ \\
Probably yes & $14(15.4 \%)$ \\
Definitely yes & $37(40.7 \%)$ \\
needed $(n, \%)$ & $36(39.6 \%)$ \\
Definitely not & \\
Probably not & \\
Maybe & $3(3.3 \%)$ \\
Probably yes & $4(4.4 \%)$ \\
Definitely yes & $12(13.2 \%)$ \\
& $18(19.8 \%)$ \\
\hline
\end{tabular}


Table 3. Cont.

\begin{tabular}{|c|c|}
\hline Variable & Participants $(N=91)$ \\
\hline \multicolumn{2}{|l|}{ Taken seriously in healthcare setting } \\
\hline Never & $34(37.4 \%)$ \\
\hline Rarely & $21(23.1 \%)$ \\
\hline Sometimes & $19(20.9 \%)$ \\
\hline Often & $11(12.1 \%)$ \\
\hline Very often & $6(6.6 \%)$ \\
\hline \multicolumn{2}{|c|}{ Misgendered by healthcare workers (HCW) } \\
\hline Never & $37(41.1 \%)$ \\
\hline Rarely & $17(18.9 \%)$ \\
\hline Sometimes & $17(18.9 \%)$ \\
\hline Often & $10(11.1 \%)$ \\
\hline Very often & $9(10.0 \%)$ \\
\hline \multicolumn{2}{|l|}{ Violence by HCW } \\
\hline Yes & $7(7.7 \%)$ \\
\hline No & $84(92.3 \%)$ \\
\hline \multicolumn{2}{|l|}{ Denial by HCW } \\
\hline Yes & $12(13.2 \%)$ \\
\hline No & $79(86.8 \%)$ \\
\hline \multicolumn{2}{|l|}{ Reported incident with HCW } \\
\hline Yes & $2(4.9 \%)$ \\
\hline No & $39(95.1 \%)$ \\
\hline \multicolumn{2}{|l|}{ Subjectively most problematic HCW } \\
\hline Physicians & $36(58.1 \%)$ \\
\hline Nurses & $6(9.7 \%)$ \\
\hline Medical-technical personnel & $3(4.8 \%)$ \\
\hline Psychologists & $11(17.7 \%)$ \\
\hline Speech therapists & $0(0.0 \%)$ \\
\hline Other & $6(9.7 \%)$ \\
\hline
\end{tabular}

\subsection{Physician-Patient Relationship}

The physician-patient relationship was evaluated using the Patient-Doctor Relationship Questionnaire 9 (PDRQ-9). The mean score on this standardized questionnaire was $33.55(\mathrm{SD}=8.83)$ out of a possible 45 points, where non-binary participants showed a lower score $(\mathrm{M}=30.79 ; \mathrm{SD}=7.46)$ than trans women $(\mathrm{M}=34.78 ; \mathrm{SD}=9.17)$ and trans men $(M=36.10 ; S D=9.45)$. After a non-significant Levene statistic confirmed homogeneity of variance between these three gender identity groups, a one-way ANOVA showed a significant difference in means $(\mathrm{F}=3.52, \mathrm{df}=2, p=0.034)$. A post-hoc Tukey HSD revealed a significant difference in means between non-binary participants and trans men (Table 4).

Table 4. Tukey HSD post-hoc correction of ANOVA comparing mean PDRQ-9 scores of different gender identity categories.

\begin{tabular}{|c|c|c|c|c|c|}
\hline $\begin{array}{l}\text { Gender Identity } \\
\text { Group (A) }\end{array}$ & $\begin{array}{l}\text { Gender Identity } \\
\text { Group (B) }\end{array}$ & $\begin{array}{l}\text { Mean Difference } \\
(\mathrm{A}-\mathrm{B})\end{array}$ & $p$ & Cohen's d (SMD *) & $\begin{array}{c}\text { 95\% Confidence } \\
\text { Interval (Lower } \\
\text { Bound, Upper } \\
\text { Bound) }\end{array}$ \\
\hline \multirow{2}{*}{ Trans men } & Trans women & 1.32 & 0.85 & 0.15 & $-4.36,7.00$ \\
\hline & Non-binary & 5.31 & 0.04 & 0.60 & $0.31,10.32$ \\
\hline \multirow{2}{*}{ Trans women } & Trans men & -1.32 & 0.85 & -0.15 & $-7.00,4.36$ \\
\hline & Non-binary & 3.99 & 0.19 & 0.45 & $-1.42,9.41$ \\
\hline \multirow{2}{*}{ Non-binary } & Trans men & -5.31 & 0.04 & -0.60 & $-10.32,-0.31$ \\
\hline & Trans women & -3.99 & 0.19 & -0.45 & $-9.41,1.42$ \\
\hline
\end{tabular}

$* \mathrm{SMD}=$ standardized mean difference. 


\section{Discussion}

The findings of this exploratory cross-sectional study outline experiences and interactions in the healthcare system of TNB patients in Austria. The results present a broad scope of experiences and healthcare utilization, which are novel outcomes compared to other studies that traditionally focused on sexually transmitted illnesses or specific mental health outcomes.

In our sample more than two thirds of participants reported being never or rarely taken seriously with regard to their gender identity in healthcare settings. Moreover, one fifth reported being very often or often misgendered by HCW. Alarmingly, $13 \%$ reported having been denied medical care due to their gender identity and 7\% experienced violence. Physicians were by far the most commonly identified as the HCW group with which participants experienced the most issues. Our results echo various other reports consistently outlining that TNB people experience stigmatization and discrimination in healthcare settings. Results of the 2015 US Transgender Survey showed that more than one third of transgender individuals reported being mistreated in the past year within healthcare systems, which included various negative experiences ranging from disrespectful treatment to verbal harassment and refusal of treatment [9]. Similar results were reported in Europe, where the results of the Trans Health Survey from Georgia, Poland, Serbia, Spain, and Sweden showed that $25 \%$ of participants felt discriminated against by a healthcare provider in the past year. The most common issues were reported as lack of knowledge by $48 \%$ of participants and $42 \%$ reporting misgendering (i.e., using incorrect names or pronouns) [37]. These results are in accordance with previous research and reaffirm the need for an immediate inclusion of curriculum elements focusing on care of TNB patients [7]. Moreover, as more and more young people are identifying with more fluid concepts of gender (up to $6 \%$ of 12-17-year-olds) [38], the visibility of non-cisgender identities is rising, which will additionally bring physicians and other HCW in more direct contact with TNB patients. Practitioners from various medical fields have already voiced the need to establish guidelines and less gendered language in their respective fields $[39,40]$. HCW can create safe and supportive environments by using correct names and pronouns, keeping in mind the evolving nature of gender identities. Simple changes in terminology and sensitive use of language can help maintain affirmative care [41].

Non-binary people reported overall lower scores on the PDRQ-9 compared to trans men and trans women. Similar findings were reported by Kittari and colleagues, who reported that non-binary people were less likely to have a healthcare provider who was aware of their gender identity and treated them with respect [7]. However, another study by the same author reported that non-binary people were less likely to postpone seeking medical care due to fear of discrimination compared to trans women [42]. A possible reason may be that non-binary individuals are less likely to come out (i.e., disclose) to their healthcare providers at all [7]. Furthermore, some authors have postulated that non-binary and transgender people who identify further from the binary concept of sex (i.e., male/female) experience greater levels of discrimination. This may explain why nonbinary people experienced lower scores on the PDRQ-9 score in the present findings [43]. Moreover, it outlines the need to educate HCWs and continue discussions in the medical field around the topics of diverse identities and intersectionality.

Of the participants who underwent gender-affirming surgery, $92.5 \%$ did so in Austria, and almost all were receiving hormone treatment and $74 \%$ planned to have further medical procedures in Austria. This, combined with relatively short waiting times compared with international experiences, indicates high-quality TNB care in Austria, as access to genderaffirming care is shown to have an influence on quality of life and health outcomes in TNB patients [44-47].

Finally, our results should be viewed in light of certain limitations. The cross-sectional study design does not allow for causal inference. Further, a sampling bias might have led to a skewed sample of participants who were more connected within the larger TNB community, with the snowballing method likely also influencing sample composition. 
Given the sensitive nature of some of the questions regarding experienced violence and discrimination, there may be some reporting bias whereby some participants may have felt uncomfortable indicating that they had experienced such incidents, which may have led to additional data distortion. In addition, as anecdotal evidence suggests that TNB people in Austria tend to avoid contact with the healthcare system out of fear of being judged and mistreated, it is possible that our sample overrepresented participants who were healthy and felt safe.

However, this study is the first of its kind from Austria, providing a much-needed exploratory and descriptive analysis of experiences within and interactions with the healthcare system and healthcare professionals. While we recognize the limited sample size of this study, it is our hope that our work will serve as a foundation for larger and more comprehensive analyses of TNB patient experiences of the Austrian healthcare system and will encourage systemic changes in practice and medical professionals' behavior to provide supportive and targeted medical care that appropriately supports these communities.

\section{Conclusions}

The results of our exploratory study show a range of experiences that transgender and non-binary patients have in Austrian healthcare settings. The results indicate that the reported experiences are still challenging despite the growing visibility and social and legal recognitions. A high proportion of our participants reported not having access to affirming care. Comparisons of patient-physician interactions suggest that non-binary people report worse experiences, which may be explained by a lack of awareness of healthcare workers regarding evolving gender identities. Given the exploratory nature of our study, we were not able to include detailed questions of lived experiences. Therefore, qualitative and mixed-methods studies providing insights into personal experiences would be valuable and support further validity of questionnaire-based studies. Overall, more educational efforts both at medical school level and ongoing medical education, coupled with raising overall societal awareness, should be implemented to improve experiences of TNB patients in Austria.

Author Contributions: Conceptualization, L.M. and I.G.; methodology, L.M.; validation, I.G.; formal analysis, L.M. and S.S.; investigation, L.M.; resources, I.G.; data curation, L.M.; writing-original draft preparation, L.M., D.T.M. and I.G.; writing-review and editing, L.M., D.T.M., S.S., R.S.-R., D.I., L.S., L.Y., K.K., R.C. and I.G.; supervision, D.T.M. and I.G.; project administration, L.M. and I.G. All authors have read and agreed to the published version of the manuscript.

Funding: This research received no external funding.

Institutional Review Board Statement: The study was conducted according to the guidelines of the Declaration of Helsinki, and approved by the Ethics Committee of the Medical University of Vienna (protocol code 1199/2020 on the 31.03.2020).

Informed Consent Statement: Informed consent was obtained from all subjects involved in the study. Data is presented in anonymous form, rendering re-identification of individual participants impossible.

Data Availability Statement: Limited dataset is available upon reasonable request from the corresponding author.

Acknowledgments: The authors would like to extend their gratitude to Aren and Ems Sakata for their help during the preparation of the questionnaire.

Conflicts of Interest: The authors declare no conflict of interest.

\section{References}

1. Devor, A.; Haefele-Thomas, A. Transgender-A Reference Book; ABC-CLIO: Santa Barbara, CA, USA, 2019.

2. Bockting, W.; Robinson, B.; Benner, A.; Scheltema, K. Patient satisfaction with transgender health services. J. Sex Marital Ther. 2004, 30, 277-294. [CrossRef] [PubMed]

3. Kcomt, L. Profound health-care discrimination experienced by transgender people: Rapid systematic review. Soc. Work Health Care 2019, 58, 201-219. [CrossRef] [PubMed] 
4. Rachlin, K.; Green, J.; Lombardi, E. Utilization of health care among female-to-male transgender individuals in the United States. J. Homosex. 2008, 54, 243-258. [CrossRef]

5. Lombardi, E. Substance use treatment experiences of transgender/transsexual men and women. J. LGBT Health Res. 2007, 3, 37-47. [CrossRef] [PubMed]

6. Snelgrove, J.W.; Jasudavisius, A.M.; Rowe, B.W.; Head, E.M.; Bauer, G.R. "Completely out-at-sea" with "two-gender medicine": A qualitative analysis of physician-side barriers to providing healthcare for transgender patients. BMC Health Serv. Res. 2012, 12, 110. [CrossRef] [PubMed]

7. Kattari, S.K.; Bakko, M.; Hecht, H.K.; Kattari, L. Correlations between healthcare provider interactions and mental health among transgender and nonbinary adults. SSM Popul. Health 2020, 10, 100525. [CrossRef] [PubMed]

8. Grant, J.M.; Mottet, L.A.; Harrison, J.; Herman, J.L.; Kiesling, M. Injustice at Every Turn: A Report of the National Transgender Discrimination Survey; National Center for Transgender Equality and National Gay and Lesbian Task Force: Washington, DC, USA, 2011.

9. James, S.E.; Herman, J.L.; Rankin, S.; Keisling, M.; Mottet, L.; Anafi, M. The Report of the 2015 U.S. Transgender Survey; National Center for Transgender Equality: Washington, DC, USA, 2016.

10. Rimes, K.A.; Goodship, N.; Ussher, G.; Baker, D.; West, E. Non-binary and binary transgender youth: Comparison of mental health, self-harm, suicidality, substance use and victimization experiences. Int. J. Transgenderism 2019, 20, 230-240. [CrossRef] [PubMed]

11. Owen-Smith, A.A.; Sineath, C.; Sanchez, T.; Dea, R.; Giammattei, S.; Gillespie, T.; Helms, M.F.; Hunkeler, E.M.; Quinn, V.P.; Roblin, D.; et al. Perception of Community Tolerance and Prevalence of Depression among Transgender Persons. J. Gay Lesbian Ment. Health 2017, 21, 64-76. [CrossRef] [PubMed]

12. World Health Organization. WHO/Europe Brief-Transgender Health in the Context of ICD-11. Available online: https: //www.euro.who.int/en/health-topics/health-determinants/gender/gender-definitions/whoeurope-brief-transgenderhealth-in-the-context-of-icd-11 (accessed on 28 May 2021).

13. Tucker, R.P.; Testa, R.J.; Simpson, T.L.; Shipherd, J.C.; Blosnich, J.R.; Lehavot, K. Hormone therapy, gender affirmation surgery, and their association with recent suicidal ideation and depression symptoms in transgender veterans. Psychol. Med. 2018, 48, 2329-2336. [CrossRef] [PubMed]

14. Olson, K.R.; Durwood, L.; DeMeules, M.; McLaughlin, K.A. Mental Health of Transgender Children Who Are Supported in Their Identities. Pediatrics 2016, 137, e20153223. [CrossRef]

15. Kattari, S.K.; Walls, N.E.; Speer, S.R.; Kattari, L. Exploring the relationship between transgender-inclusive providers and mental health outcomes among transgender/gender variant people. Soc. Work Health Care 2016, 55, 635-650. [CrossRef]

16. Riggs, D.W.; Coleman, K.; Due, C. Healthcare experiences of gender diverse Australians: A mixed-methods, self-report survey. BMC Public Health 2014, 14, 230. [CrossRef] [PubMed]

17. Chisolm-Straker, M.; Willging, C.; Daul, A.D.; McNamara, S.; Sante, S.C.; Shattuck, D.G., 2nd; Crandall, C.S. Transgender and Gender-Nonconforming Patients in the Emergency Department: What Physicians Know, Think, and Do. Ann. Emerg. Med. 2018, 71, 183-188. [CrossRef]

18. Vermeir, E.; Jackson, L.A.; Marshall, E.G. Improving Healthcare Providers' Interactions with Trans Patients: Recommendations to Promote Cultural Competence. Healthc. Policy 2018, 14, 11-18. [CrossRef] [PubMed]

19. Grabovac, I.; Abramovic, M.; Komlenovic, G.; Milosevic, M.; Mustajbegovic, J. Attitudes towards and knowledge about homosexuality among medical students in Zagreb. Coll. Antropol. 2014, 38, 39-45. [PubMed]

20. Prairie, T.M.; Wrye, B.; Murfree, S. Intersections of Physician Autonomy, Religion, and Health Care When Working With LGBT+ Patients. Health Promot. Pract. 2018, 19, 542-549. [CrossRef] [PubMed]

21. Patterson, J.G.; Jabson Tree, J.M.; Kamen, C. Cultural competency and microaggressions in the provision of care to LGBT patients in rural and appalachian Tennessee. Patient Educ. Couns. 2019, 102, 2081-2090. [CrossRef] [PubMed]

22. Bauer, G.R.; Hammond, R.; Travers, R.; Kaay, M.; Hohenadel, K.M.; Boyce, M. "I don't think this is theoretical; this is our lives": How erasure impacts health care for transgender people. J. Assoc. Nurses AIDS Care 2009, 20, 348-361. [CrossRef] [PubMed]

23. Poteat, T.; German, D.; Kerrigan, D. Managing uncertainty: A grounded theory of stigma in transgender health care encounters. Soc. Sci. Med. 2013, 84, 22-29. [CrossRef] [PubMed]

24. Zeluf, G.; Dhejne, C.; Orre, C.; Nilunger Mannheimer, L.; Deogan, C.; Höijer, J.; Ekéus Thorson, A. Health, disability and quality of life among trans people in Sweden-a web-based survey. BMC Public Health 2016, 16, 903. [CrossRef]

25. Lev, A.I. Disordering gender identity: Gender identity disorder in the DSM-IV-TR. J. Psychol. Hum. Sex. 2005, 17, 35-69. [CrossRef]

26. Dewey, J.M. Knowledge legitimacy: How trans-patient behavior supports and challenges current medical knowledge. Qual. Health Res. 2008, 18, 1345-1355. [CrossRef]

27. Federal Ministry of Women and Health. Empfehlungen für den Behandlugsprozess bei Geschlechtsdysphorie bzw. Transsexualismus nach der Klassifikation in der derzeit gültigen DSM bzw ICD-Fassung; Vienna, Austria. 2017. Available online: https://www.sozialministerium.at/Themen/Gesundheit/Nicht-uebertragbare-Krankheiten/Psychische-Gesundheit/ Transsexualismus-Geschlechtsdysphorie.html (accessed on 25 May 2021).

28. ILGA-Europe-The European Region of the International Lesbian, Gay, Bisexual, Trans and Intersex Association. Annual Review of the Human Rights Situation of Lesbian, Gay, Bisexual, Trans, and Intersex People in Austria. Available online: https:/ / rainbow-europe.org/\#8621/0/0 (accessed on 6 December 2020). 
29. Organisation for Economic Co-operation and Development. Over the Rainbow? The Road to LGBTI Inclusion. How Does Austria Compare? Available online: https:/ / www.oecd.org/austria/OECD-LGBTI-2020-Over-The-Rainbow-AUSTRIA.pdf (accessed on 11 June 2021).

30. European Union Agency for Fundamental Rights. EU LGBTI survey II-A long Way to go for LGBTI Equality. Country Data-Austria; Publication Office of the European Union: Luxembourg, 2020.

31. Whittle, S.; Turner, L.; Combs, R.; Rhodes, S. Transgender EuroSurvey: Legal Survey and Focus on the Transgender Experience of Health Care; ILGA Europe and TGEU: Bruxelles, Belgium, 2008.

32. Eyssel, J.; Koehler, A.; Dekker, A.; Sehner, S.; Nieder, T.O. Needs and concerns of transgender individuals regarding interdisciplinary transgender healthcare: A non-clinical online survey. PLoS ONE 2017, 12, e0183014. [CrossRef] [PubMed]

33. The GenIUSS Group. Best Practices for Asking Questions to Identify Transgender and Other Gender Minority Respondents on PopulationBased Surveys (GenIUSS); The Williams Institute: Los Angeles, CA, USA, 2014.

34. Van der Feltz-Cornelis, C.M.; Van Oppen, P.; Van Marwijk, H.W.; De Beurs, E.; Van Dyck, R. A patient-doctor relationship questionnaire (PDRQ-9) in primary care: Development and psychometric evaluation. Gen. Hosp. Psychiatry 2004, 26, 115-120. [CrossRef]

35. Porcerelli, J.H.; Murdoch, W.; Morris, P.; Fowler, S. The Patient-Doctor Relationship Questionnaire (PDRQ-9) in Primary Care: A Validity Study. J. Clin. Psychol. Med. Settings 2014, 21, 291-296. [CrossRef]

36. Zenger, M.; Schaefert, R.; van der Feltz-Cornelis, C.; Brahler, E.; Hauser, W. Validation of the Patient-Doctor-Relationship Questionnaire (PDRQ-9) in a representative cross-sectional German population survey. PLoS ONE 2014, 9, e91964. [CrossRef] [PubMed]

37. Smiley, A.; Burgwal, A.; Orre, C.; Summanen, E.; Nieto Garcia, I.; Vidic, J.; Motmans, J.; Kata, J.; Gvianishvili, N.; Hard, V.; et al. Overdiagnosed but Underserved. Trans Healthcare in Georgia, Poland, Serbia, Spain and Sweden: Trans Health Survey; Transgender Europe: Berlin, Germany, 2017.

38. Wilson, B.M.D.; Choi, S.K.; Herman, J.L.; Becker, T.L.; Conron, K.J. Characteristics and Mental Health of Gender Nonconforming Adolescents in California. Available online: https:/ / williamsinstitute.law.ucla.edu/publications/gnc-youth-ca/ (accessed on 28 May 2021).

39. Stroumsa, D.; Wu, J.P. Welcoming transgender and nonbinary patients: Expanding the language of "women's health". Am. J. Obstet. Gynecol. 2018, 219, 585.e1-585.e5. [CrossRef]

40. Shires, D.A.; Stroumsa, D.; Jaffee, K.D.; Woodford, M.R. Primary Care Clinicians' Willingness to Care for Transgender Patients. Ann. Fam. Med. 2018, 16, 555-558. [CrossRef]

41. Casey, C.F. Providing primary care to transgender patients. Fam. Med. Community Health 2019, 7, e000130. [CrossRef] [PubMed]

42. Kattari, S.K.; Atteberry-Ash, B.; Kinney, M.K.; Walls, N.E.; Kattari, L. One size does not fit all: Differential transgender health experiences. Soc. Work Health Care 2019, 58, 899-917. [CrossRef] [PubMed]

43. Goldberg, A.E.; Kuvalanka, K.A.; Budge, S.L.; Benz, M.B.; Smith, J.Z. Health Care Experiences of Transgender Binary and Nonbinary University Students. Couns. Psychol. 2019, 47, 59-97. [CrossRef]

44. Lindqvist, E.K.; Sigurjonsson, H.; Möllermark, C.; Rinder, J.; Farnebo, F.; Lundgren, T.K. Quality of life improves early after gender reassignment surgery in transgender women. Eur. J. Plast. Surg. 2017, 40, 223-226. [CrossRef]

45. El-Hadi, H.; Stone, J.; Temple-Oberle, C.; Harrop, A.R. Gender-Affirming Surgery for Transgender Individuals: Perceived Satisfaction and Barriers to Care. Plast. Surg. 2018, 26, 263-268. [CrossRef] [PubMed]

46. Fielding, J.; Bass, C. Individuals seeking gender reassignment: Marked increase in demand for services. BJPsych. Bull. 2018, 42, 206-210. [CrossRef] [PubMed]

47. Weinforth, G.; Fakin, R.; Giovanoli, P.; Nunez, D.G. Quality of Life Following Male-To-Female Sex Reassignment Surgery. Dtsch Arztebl. Int. 2019, 116, 253-260. [CrossRef] 